\title{
Video Article \\ Development and Validation of an Ultrasensitive Single Molecule Array Digital Enzyme-linked Immunosorbent Assay for Human Interferon-a
}

\author{
Alba Llibre ${ }^{\star^{1,2}}$, Vincent Bondet* ${ }^{{ }^{1,2}}$, Mathieu P. Rodero ${ }^{3}$, David Hunt ${ }^{4}$, Yanick J. Crow ${ }^{3,5}$, Darragh Duffy ${ }^{1,2}$ \\ ${ }^{1}$ Immunobiology of Dendritic Cells, Institut Pasteur \\ 2 INSERM U1223 \\ ${ }^{3}$ Laboratory of Neurogenetics and Neuroinflammation, INSERM UMR1163, Institut Imagine \\ ${ }^{4}$ MRC Human Genetics Unit, MRC Institute of Genetics and Molecular Medicine, University of Edinburgh \\ ${ }^{5}$ Manchester Centre for Genomic Medicine, University of Manchester \\ * These authors contributed equally
}

Correspondence to: Darragh Duffy at darragh.duffy@pasteur.fr

URL: https://www.jove.com/video/57421

DOI: doi: $10.3791 / 57421$

Keywords: Immunology and Infection, Issue 136, Digital ELISA, protein biomarkers, interferon, antibodies, cytokines, high sensitivity

Date Published: 6/14/2018

Citation: Llibre, A., Bondet, V., Rodero, M.P., Hunt, D., Crow, Y.J., Duffy, D. Development and Validation of an Ultrasensitive Single Molecule Array Digital Enzyme-linked Immunosorbent Assay for Human Interferon-a. J. Vis. Exp. (136), e57421, doi:10.3791/57421 (2018).

\section{Abstract}

The main aim of this protocol is to describe the development and validation of an interferon (IFN)- $\alpha$ single molecule array digital Enzyme-Linked ImmunoSorbent Assay (ELISA) assay. This system enables the quantification of human IFN-a protein with unprecedented sensitivity, and with no cross-reactivity for other species of IFN.

The first key step of the protocol is the choice of the antibody pair, followed by the conjugation of the capture antibody to paramagnetic beads, and biotinylation of the detection antibody. Following this step, different parameters such as assay configuration, detector antibody concentration, and buffer composition can be modified until optimum sensitivity is achieved. Finally, specificity and reproducibility of the method are assessed to ensure confidence in the results. Here, we developed an IFN- $\alpha$ single molecule array assay with a limit of detection of $0.69 \mathrm{fg} / \mathrm{mL} \mathrm{using}$ high-affinity autoantibodies isolated from patients with biallelic mutations in the autoimmune regulator (AIRE) protein causing autoimmune polyendocrinopathy syndrome type 1/autoimmune polyendocrinopathy-candidiasis-ectodermal dystrophy (APS1/APECED). Importantly, these antibodies enabled detection of all 13 IFN- $\alpha$ subtypes.

This new methodology allows the detection and quantification of IFN- $\alpha$ protein in human biological samples at attomolar concentrations for the first time. Such a tool will be highly useful in monitoring the levels of this cytokine in human health and disease states, most particularly infection, autoimmunity, and autoinflammation.

\section{Video Link}

The video component of this article can be found at https://www.jove.com/video/57421/

\section{Introduction}

Type I IFNs are a family of cytokines which play a central role in orchestrating antiviral immune responses. They were first discovered by Isaacs and Lindenmann 60 years ago ${ }^{1,2}$ and it is now known that this heterogeneous family of polypeptides comprises 14 different subclasses (13 IFN- $\alpha$ subtypes and 1 IFN- $\beta$ ). Type I IFNs are essential to the clearance of viral infections, but have also been implicated in the pathology of a variety of human disease states, including the autoimmune disorders systemic lupus erythematosus (SLE), juvenile dermatomyositis (JDM), and the type I interferonopathies in which constitutive type I IFN-induced signaling results in pathology $3,4,5,6,7$.

Studying type I IFN protein levels in biological samples has been challenging since its initial identification as an "interfering substance" ${ }^{1,2}$ Currently, sandwich Enzyme-Linked ImmunoSorbent Assay (ELISA) is the most widely used method for detection of IFN-a protein. Despite being specific, simple, and rapid, type I IFN ELISAs present important limitations, such as limited sensitivity. In addition, the measurement of all IFNa subtypes requires the use of multiple assays each with their own detection capacity and sensitivity. While there are commercial ELISAs that detect different subtypes of IFN- $\alpha$, their sensitivity is limited $(1.95 \mathrm{pg} / \mathrm{mL}, 12.5 \mathrm{pg} / \mathrm{mL}$, and $12.5 \mathrm{pg} / \mathrm{mL}$, respectively) which is often insufficient to detect IFN- $\alpha$ protein in biological samples. To overcome this limitation, several biological proxy assays have been developed to quantify type I IFN by measuring induced gene expression or functional activity ${ }^{8,9,10,11,12,13,14}$. Nonetheless, these assays do not provide a direct measurement of the IFN- $\alpha$ protein.

In this study, single molecule array digital ELISA technology was used to develop an assay for the detection of single IFN- $\alpha$ protein molecules. Digital ELISA utilizes the same basic chemistry as conventional ELISA, however, the reaction takes place in arrays comprising 50,000 individual 46 femtoliter sized wells ${ }^{15,16}$. Single protein molecules are captured by antibody-coated paramagnetic beads and labeled with a biotinylated 
detection antibody, followed by binding of an enzyme conjugate, streptavidin- $\beta$-galactosidase (SBG). Subsequently, the beads are suspended with a fluorogenic enzyme substrate, resorufin- $\beta$-D-galactopyranoside (RGP), into single-molecule arrays. By decreasing the volume reaction 2 billion times ${ }^{17}$, a high local concentration of fluorescent signal is achieved and single molecule counts become feasible, as each molecule generates a signal that can now be reliably measured ${ }^{18}$. In essence single molecule arrays are capable of counting single immunocomplexes and determining an average number of enzymes per bead (AEB). Counting the microwells in which a signal is detected permits quantification/ digitalization of protein molecules, as there is a direct correlation between protein concentration and the ratio between immunocomplexed-beads and a total number of beads present in the femtoliter-sized chambers.

Yeung et al. performed an extensive cross-platform evaluation study using nine different technologies and four cytokine immunoassays with the aim of comparing assay precision, sensitivity, and data correlation across the different platforms ${ }^{19}$. One of the key findings of the study was that single molecule arrays and single molecule counting immunoassay presented the highest sensitivity for detection of cytokines in human serum within the sub-pg/mL concentration range. Single molecule array digital ELISA cytokine assays have been used to study the role of TNF- $\alpha$ and IL-6 in Crohn's disease ${ }^{20}$, IFN- $\alpha$ in interferonopathy and auto-immune patients ${ }^{7}$, and the different post-translationally modified forms of C-XC motif chemokine 10 (CXCL10) in chronic hepatitis and healthy donors receiving sitagliptin ${ }^{21,22}$. Other applications include measurement of rhodopsin in patients with diabetic retinopathy ${ }^{23}$; the study of brain pathologies through serum/plasma measurements of neurofilament light ${ }^{24}$ and amyloid- $\beta$ 1-42 peptide ${ }^{25}$, in the context of multiple sclerosis and Alzheimer's disease, respectively. Single molecule array assays can also be used for improved pathogen detection such as characterization of the HIV viral reservoir ${ }^{26}$, and also for detection of DNA ${ }^{27}$ and micro RNAs ${ }^{28}$. A major advantage of the single molecule array technology is this high versatility, as an assay against any analyte of interest can be developed if a specific antibody pair is available. In addition, homebrew assay kits are commercially available, allowing the development of new assays, the protocol of which is detailed in a modified form below.

Here, a detailed description of the development and validation steps for a single molecule array assay is presented that results in enhanced sensitivity for IFN- $\alpha$ protein detection. Antibodies for single molecule array assays should be highly specific, avoiding cross reactivity with related proteins (with species specificity considered if relevant). Ideally, antibodies with a $K_{D}$ smaller than $10^{-9} \mathrm{M}$ should be chosen; high affinity ensures strong binding, with the production of a higher signal. The kinetics of the antibody-antigen binding are also important, and fast $\mathrm{K}_{\mathrm{on}}$ and slow $\mathrm{K}_{\text {off }}$ will favor antigen-antibody complex assembly. Starting with an antibody pair that has a good performance in classical ELISA, with a limit of detection (LOD) of $1-100 \mathrm{pg} / \mathrm{mL}$, increases the chances of obtaining a highly sensitive single molecule array assay. Chang and colleagues performed detailed kinetic studies of the biomolecular interactions occurring at every single step, proposing a set of equations to predict analytical sensitivity ${ }^{18}$. They showed that single molecule array digital ELISA appears to be effective within a broad range of antibody affinities $\left(K D \sim 10^{-11}-10^{-9} \mathrm{M}\right)$, as well as that signal generation is more dependent on the on-rate of such antibodies.

To utilize high affinity antibodies we took advantage of antibodies isolated from patients with the autoimmune polyendocrinopathy syndrome type 1/autoimmune polyendocrinopathy-candidiasis-ectodermal dystrophy (APS1/APECED) ${ }^{29}$. For reasons that are not yet understood, the large majority of AIRE-deficient individuals develop a core set of high-avidity antibodies against all IFN- $\alpha$ subtypes ${ }^{29}$, and we selected two anti-IFN- $\alpha$ antibody clones of complementary binding affinities for the different IFN- $\alpha$ subtypes, as estimated by IC ${ }_{50}$ values. The combination of these unique high-affinity antibodies with single molecule array technology enabled the direct quantification of IFN- $\alpha$ at attomolar (fg/mL) concentrations. Such ultrasensitive IFN- $\alpha$ protein detection will contribute to a better understanding of the nature, regulation and biological impact of the IFN-induced response in different disease settings.

\section{Selection of Antibodies}

1. Before beginning the protocol review all key steps (Table 1) and select optimum antibodies. NOTE: For this protocol high affinity anti-IFN- $\alpha$ antibodies - the IC50 of which are described in Table 2 were selected. Preferentially, choose a pair that works well with conventional ELISA.

\section{Conjugation of Capture Antibody to Paramagnetic Beads and Testing of Different Concentrations}

NOTE: Always keep Bead Conjugation Buffer (BCB) and Bead Wash Buffer (BWB) on the ice during the antibody conjugation process.

\section{Capture Antibody Buffer Exchange}

1. Take initial quantities of anti-IFN- $\alpha$ antibody $A$ to test 3 different bead conjugations ratios $(0.038 \mathrm{mg} / \mathrm{mL}, 0.075 \mathrm{mg} / \mathrm{mL}$, and $0.3 \mathrm{mg} / \mathrm{mL})$. NOTE: Low antibody coating concentrations can be beneficial if the assay presents a high background signal. Initial antibody quantity should account for an estimated $30 \%$ loss during the buffer exchange process. According to manufacturer's instructions and in order to reduce initial background, concentrations of $0.05 \mathrm{mg} / \mathrm{mL}, 0.1 \mathrm{mg} / \mathrm{mL}$, and $0.3 \mathrm{mg} / \mathrm{mL}$ were tested, although these exact values were often not obtained due to the aforementioned variable loss in the buffer exchange process.

2. Add the required volume of the antibody into a filter column together with $\mathrm{BCB}$, up to $500 \mu \mathrm{L}$.

3. Centrifuge the columns at $>10,000 \times \mathrm{g}$ for $5 \mathrm{~min}$ and discard the flow-through.

4. Wash the column twice by adding a total volume of $450 \mu \mathrm{L}$ of $\mathrm{BCB}$ followed by centrifugation at $>10,000 \times \mathrm{g}$ for $5 \mathrm{~min}$ and discard the flow through.

5. Place the filter column containing the antibody into a clean microcentrifuge tube upside down - the open part of the column facing the inside of the new tube - and centrifuge at $800 \times \mathrm{g}$ for $1 \mathrm{~min}$.

NOTE: This step will allow collection of the cleaned antibody. No buffer addition is required for this step.

6. Wash the membranes with $50 \mu \mathrm{L} \mathrm{BCB}$ and centrifuge at $800 \mathrm{xg}$ for $1 \mathrm{~min}$ as in 2.1.5.

7. Measure the concentration of antibody using a low volume spectrophotometer.

8. Add BCB to achieve the desired antibody concentration and note the final volume. 
NOTE: A volume of $200 \mu \mathrm{L}$ will be used to describe the rest of the protocol, this volume being referred to as 2 volumes (2V). All the following reagent volumes will be adapted accordingly.

9. Vortex and keep on ice.

\section{Paramagnetic Bead Preparation}

1. Transfer $2.8 \times 10^{8}$ beads $(100 \mu \mathrm{L}=1 \mathrm{~V})$ into a microfuge tube.

NOTE: The volume of beads is dependent on the final volume obtained in 2.1.8.

2. Pulse spin and put in a magnetic separator for $1 \mathrm{~min}$, discard diluent, and remove from magnet.

3. Add $2 \mathrm{~V}$ of $\mathrm{BWB}$ and vortex for $5 \mathrm{~s}$.

4. Repeat 2.2.2 and 2.2.3 two times with BWB and two more times with BCB.

5. For $1 \mathrm{~V}$ of beads add $190 \mu \mathrm{L} \mathrm{BCB}$, vortex $5 \mathrm{~s}$, pulse spin, and store the washed beads on ice.

3. Bead Activation

1. Add $1 \mathrm{~mL}$ of cold BCB to a 10-mg vial of 1-ethyl-3-(3-dimethylaminopropyl) carbodiimide hydrochloride (EDC) and vortex until the solution is homogeneous.

2. For $1 \mathrm{~V}$ of beads add $10 \mu \mathrm{L}$ of cold diluted EDC to the washed beads, vortex, and keep in a shaker at $1,000 \mathrm{rpm}$ for $30 \mathrm{~min}$ at room temperature.

NOTE: EDC preparation and addition to the beads should be done as quickly as possible due to EDC instability in aqueous solutions. Also, as EDC is highly reactive, it is important to have a homogenous bead suspension before EDC addition in order to prevent heterogeneous bead activation. After EDC addition, beads must be kept in suspension.

\section{Bead Conjugation of the Antibody}

1. Vortex and pulse spin the activated beads. Now put the beads in a magnetic separator for 1 min, discard BCB supernatant, and remove the tube from the magnet.

2. Wash the beads with $2 \mathrm{~V}$ of $\mathrm{BCB}$. Vortex, pulse spin, and put in the magnetic separator for $1 \mathrm{~min}$. Then discard the $\mathrm{BCB}$ buffer and remove the beads from the magnet.

3. Quickly add the cold, buffer-exchanged $200 \mu \mathrm{L}(2 \mathrm{~V})$ of antibody to the activated beads.

4. Vortex and keep for $2 \mathrm{~h}$ in the shaker at room temperature.

\section{Bead Blocking and Final Clean-up}

1. Pulse spin the antibody-coated beads suspension, put in the magnetic separator for $1 \mathrm{~min}$, transfer the supernatant to a new tube, and measure the concentration with a low volume spectrophotometer.

NOTE: This step will provide information on whether the beads are saturated - any values above zero will indicate bead saturation - as detection of soluble antibody unable to bind to the beads will be measurable.

2. Remove the conjugated beads from the magnet, add $2 \mathrm{~V}$ of $\mathrm{BWB}$, vortex for $5 \mathrm{~s}$, pulse spin, and put in the magnetic separator for 1 min

3. Transfer the supernatant to a new tube and measure the concentration using a low volume spectrophotometer.

NOTE: This step will provide information on whether the antibodies are stably fixed to the beads. Detectable antibody concentration in this supernatant will indicate detachment of the antibody from the beads, which happens regularly. This assay often works even when very small amounts of capture antibody remain attached to the beads.

4. Remove the conjugated beads from the magnet, add $2 \mathrm{~V}$ of $\mathrm{BWB}$, vortex for $5 \mathrm{~s}$, pulse spin, and put in the magnetic separator for 1 min

5. Remove conjugated beads from the magnet, add $2 \mathrm{~V}$ of Bead Blocking Buffer, vortex for $5 \mathrm{~s}$, and incubate in the shaker for 30 min at room temperature.

6. Wash the antibody-coated and blocked beads $3 x$ with $2 \mathrm{~V}$, once with BWS, and $2 \mathrm{x}$ with Bead Diluent Buffer (discard all supernatants).

7. Store the coated and blocked beads at $4^{\circ} \mathrm{C}$ until use with $2 \mathrm{~V}$ of Bead Diluent Buffer.

NOTE: Just before use, beads must be washed once with Detector/Sample Diluent using a volume of $250 \times$ Bead volume/20, using the magnetic separator.

\section{Detection Antibody Biotinylation}

\section{Detection Antibody Buffer Exchange}

1. Take $260 \mu \mathrm{g}$ of the two anti-IFN- $\alpha$ Ab clones. NOTE: This takes into consideration a $30 \%$ loss during buffer exchange and allows testing of two different biotin/antibody ratios.

2. Proceed as 2.1 using Biotinylation Reaction Buffer (BRB) instead of BCB.

3. Measure the volume and the antibody concentrations and adjust the volume to obtain a final concentration of $1 \mathrm{mg} / \mathrm{mL}$. NOTE: This is a suggested starting concentration, but it can be optimized if the assay does not achieve the required sensitivity.

\section{Detection Antibody Biotinylation}

1. Bring the N-hydroxysuccinimide-polyethylene-glycol4-biotin (NHS-PEG4-Biotin) to room temperature and resuspend with a total of 400 $\mu \mathrm{L}$ of distilled water to achieve a $3.4 \mathrm{mM}$ concentration.

2. Decide the biotin:antibody ratio to test and mix detection antibody and diluted biotin accordingly (60:1 ratio equals $100 \mu \mathrm{L}$ of detection antibody and $4.5 \mu \mathrm{L}$ of biotin). NOTE: To begin, test $30: 1$ and $60: 1$ ratios.

3. Vortex the antibody-biotin mix, pulse spin and incubate for $30 \mathrm{~min}$ at room temperature. NOTE: No need to shake.

\section{Biotinylated Detection Antibody Purification}

1. Transfer the biotinylated antibody to a new filter and proceed as 2.1 , performing 3 washing steps with $\mathrm{BRB}(400,450$, and $450 \mu \mathrm{L})$ and a final collection. 
2. Measure the volume and concentration of the purified, biotinylated detection antibody and store at $4{ }^{\circ} \mathrm{C}$ until use.

\section{Assay Optimization}

NOTE: Use of the single molecule array analyzer software in a Homebrew configuration ${ }^{30}$.

The single molecule array analyzer machine is controlled by software that allows to run assay standardizations, to perform sample quantifications, to modify external parameters (bead, detector, SBG, RGP concentrations; sample dilutions...) and internal parameters (number of steps, incubation times...) to achieve optimal assay conditions, and can also be used to calculate results (background, LOD, quantities). For the setup of the single molecule array analyzer and to calculate the reagent volumes required for each round of optimization, see manufacturer's instructions. Perform the first rounds of optimization using a 2-step configuration.

1. Test combinations of capture antibody-conjugated beads and biotinylated detection antibody in both configurations.

1. Test combinations of the three different anti-IFN- $\alpha$ A capture antibody concentrations with the two different anti-IFN- $\alpha$ B biotinylation ratios as detection and capture antibodies, and vice versa (Figure 1) by selection of the appropriate conditions in the analyzer software.

2. Choose the most sensitive combination, that is, the conditions that offer the lowest LOD, and use it for further steps NOTE: Figure 1 shows how a $0.3 \mathrm{mg} / \mathrm{mL}$ anti-IFN- $\alpha$ A antibody bead concentration and a biotin:antibody ratio of 30:1 with the antiIFN- $\alpha$ B antibody resulted in the highest sensitivity, as evidenced by an LOD of $11.6 \mathrm{fg} / \mathrm{mL}$. (See Supplementary Table 1). This combination will be used for all future steps. Notice that the great sensitivity achieved with this particular assay before any rounds of optimization.
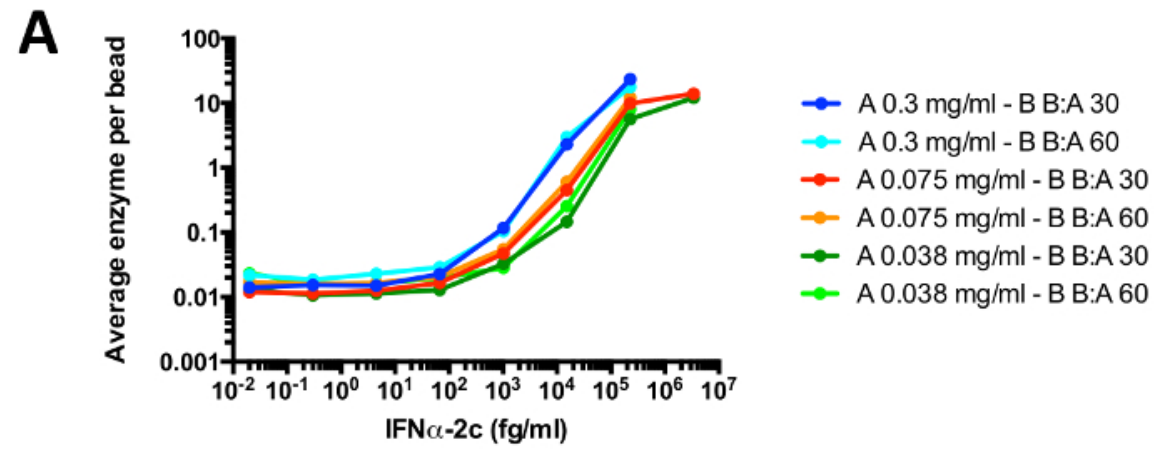

B
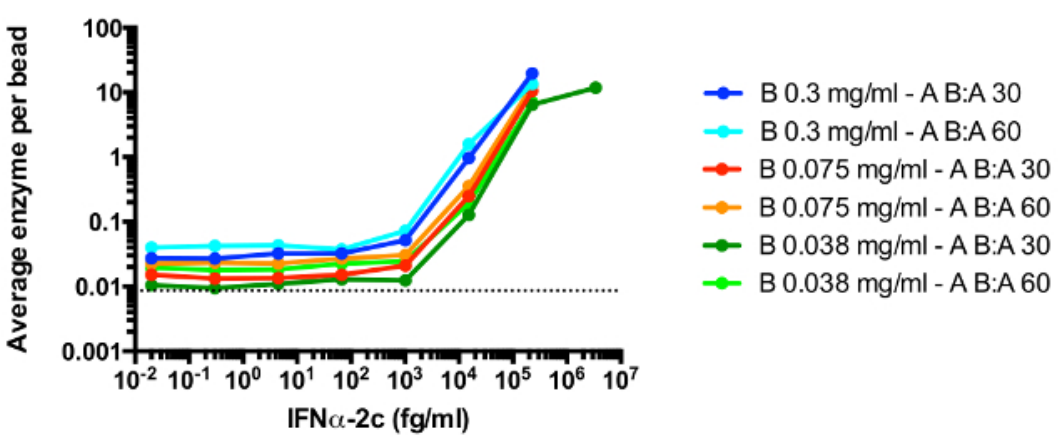

Figure 1: Selection of antibody orientation, capture antibody concentration on beads and biotinylation ratio. The two possible different configurations were tested, using the anti-IFN- $\alpha$ A as capture antibody and anti-IFN- $\alpha$ B as detection antibody (A), and vice versa (B). IFNa-2C was used as antigen. Different capture antibody concentrations as well as biotin:antibody $(B: A)$ ratios were also tested for both configurations. Dotted line shows LOD for the best condition; anti-IFN- $\alpha$ A $0.3 \mathrm{mg} / \mathrm{mL}$ as capture and anti-IFN- $\alpha$ B biotin:detector antibody ratio of 30 (LOD = $11.6 \mathrm{mg} / \mathrm{mL}$ corresponding to an AEB value of 0.017265$)$. A 2-step configuration was used. Biotin:antibody (B:A). Please click here to view a larger version of this figure.

2. Compare a 2 vs. 3-step configuration.

NOTE: In a 3-step configuration, there are three different incubation steps, one with the capture antibody, one with the detection antibody and a final third one for the SBG enzyme labeling. However, in a 2-step configuration, capture and detection antibodies are incubated simultaneously with the analyte of interest.

1. Run the Single molecule array analyzer with the capture and detector antibody concentration and ratios from 4.1 .2 selecting the 2 and 3-step configurations pre-configured in the analyser, following manufacturer's instructions ${ }^{30}$.

2. Choose the configuration that allows for the highest sensitivity and keep it for future steps 
NOTE: As shown in Figure 2 and Supplementary Table 2, the 2-step configuration gave slightly higher sensitivity and signal/ background ratio for every concentration tested. Therefore, the 2-step configuration was kept for future steps.

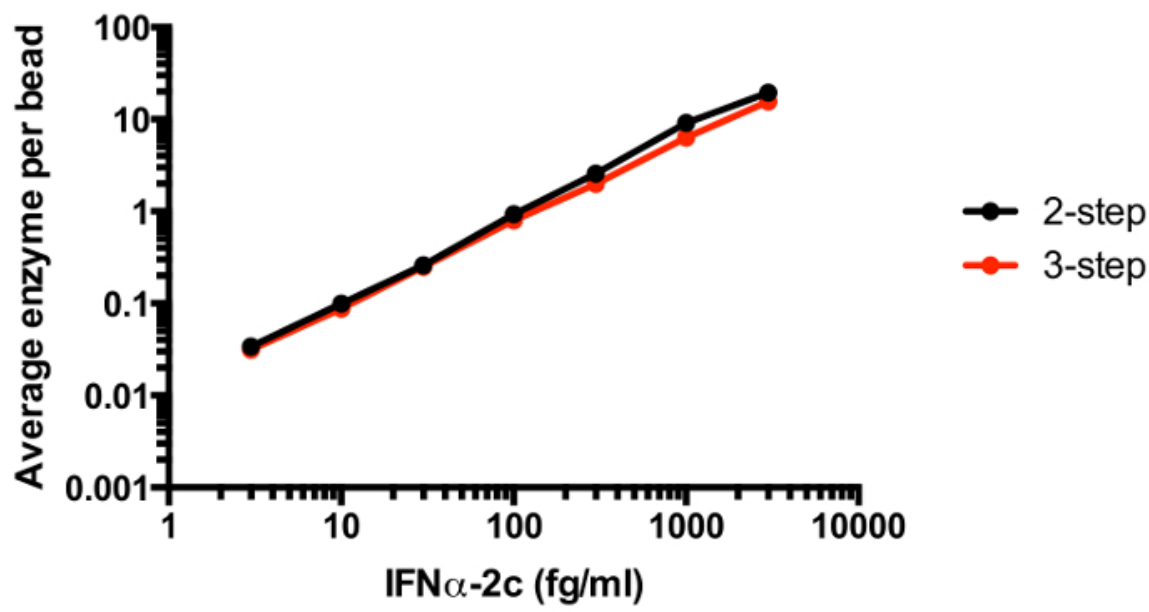

Figure 2: 2 vs 3-step configuration comparison. The 2 and 3-step configurations were assessed using $0.3 \mathrm{mg} / \mathrm{mL}$ of anti-IFN- $\alpha$ A antibody as capture and anti-IFN- $\alpha$ B as detection antibody in a 30 biotin:antibody ratio. IFNa-2c was used as antigen. In a 3 -step condition setting, there are three different incubation steps, one with the capture antibody, one with the detection antibody and a final third one for the SBG enzyme labelling. However, in a 2-step configuration, capture and detection antibodies are incubated simultaneously with the analyte of interest. Please click here to view a larger version of this figure.

3. Detector Antibody and SBG concentration optimization

1. Test three different concentrations of detector antibody $(0.1,0.3$, and $0.6 \mu \mathrm{g} / \mathrm{mL})$ together with three different concentrations of SBG $(50,150$, and $250 \mathrm{pM})$ as described above ${ }^{30}$.

2. Choose the concentrations that gives the highest sensitivity and keep them for future steps.

NOTE: Figure 3 shows that detector $0.3 \mu \mathrm{g} / \mathrm{mL}$ and SBG $150 \mathrm{pM}$ were the conditions that showed the optimal LOD. These conditions also gave low background levels and medium amplitude, a behavior that produces good standard deviation (SD) values (Supplementary Table 3). Typical concentrations range between $0.1-1 \mu \mathrm{g} / \mathrm{mL}$ for the detection antibody and $50-200 \mathrm{pM}$ for SBG, although higher concentrations (e.g. up to $300 \mathrm{pM}$ ) of the latter might be required. It is important to avoid conditions that will render backgrounds higher than $0.02 \mathrm{AEB}$. Increasing the concentration of the detector monoclonal antibody (mAb) or SBG will enhance both signal response and background. However, if the increment in signal surmounts the change in background, the LOD will improve. A situation can arise in which a decrease in background allows better discrimination between low calibrators.

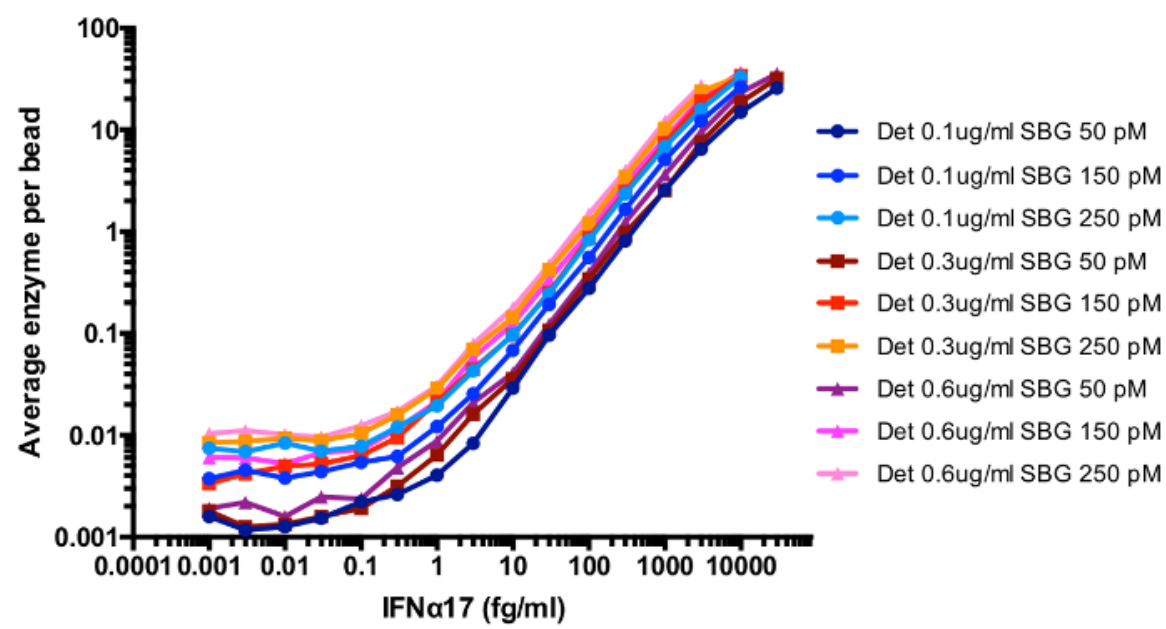

Figure 3: Detector and SBG concentration optimization. Three different concentrations of biotinylated detector antibody $(0.1,0.3$, and 0.6 $\mu \mathrm{g} / \mathrm{ml}$ ) together with three different concentrations of SBG $(50,150$, and $250 \mathrm{pM})$ were assessed. Dotted line shows LOD for the best condition; detector antibody at $0.3 \mathrm{mg} / \mathrm{mL}$ and SBG $150 \mathrm{pM}$ (LOD $=0.09 \mathrm{mg} / \mathrm{mL}$ corresponding to an AEB value of 0.017184$)$. Please click here to view a larger version of this figure.

4. Additional optimization steps

1. If the required sensitivity has not been achieved, test different incubation times for the different steps using the preconfigured options in the analyzer software.

2. If the assay is not sensitivity enough, optimize the number of beads per assay using the preconfigured options in the analyzer software. 
NOTE: Once testing of biological samples begins, sample volume is an additional parameter susceptible to optimization. Make sure that samples are handled according to the health and safety procedures.

\section{Assay Specificity and Reproducibility}

1. Test IFN- $\alpha$ assay specificity, by testing the assay with different IFN- $\alpha$ subtypes and other related proteins (Figure $\mathbf{4 a}$ and $\mathbf{4 b}$ ).

A

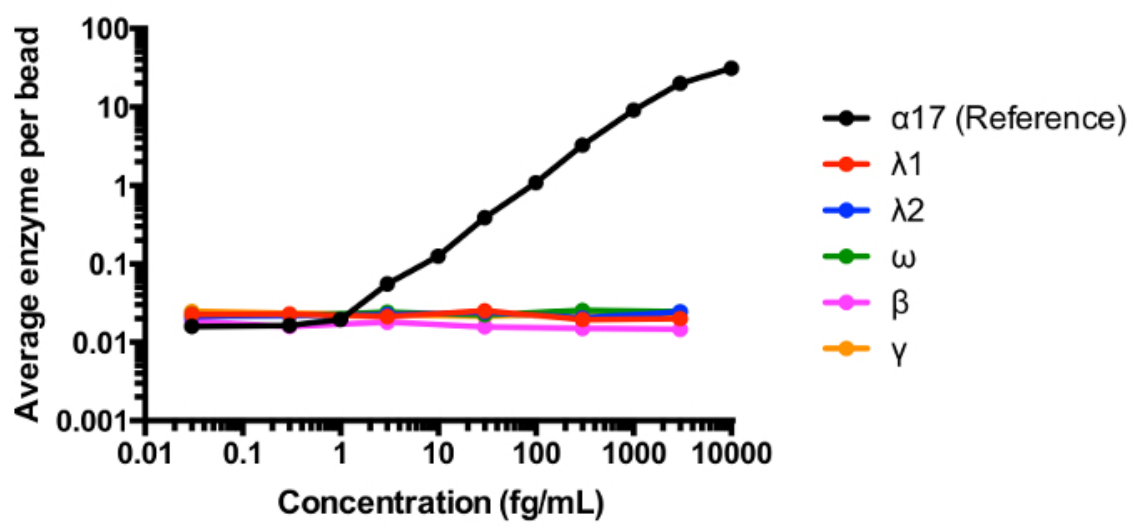

B

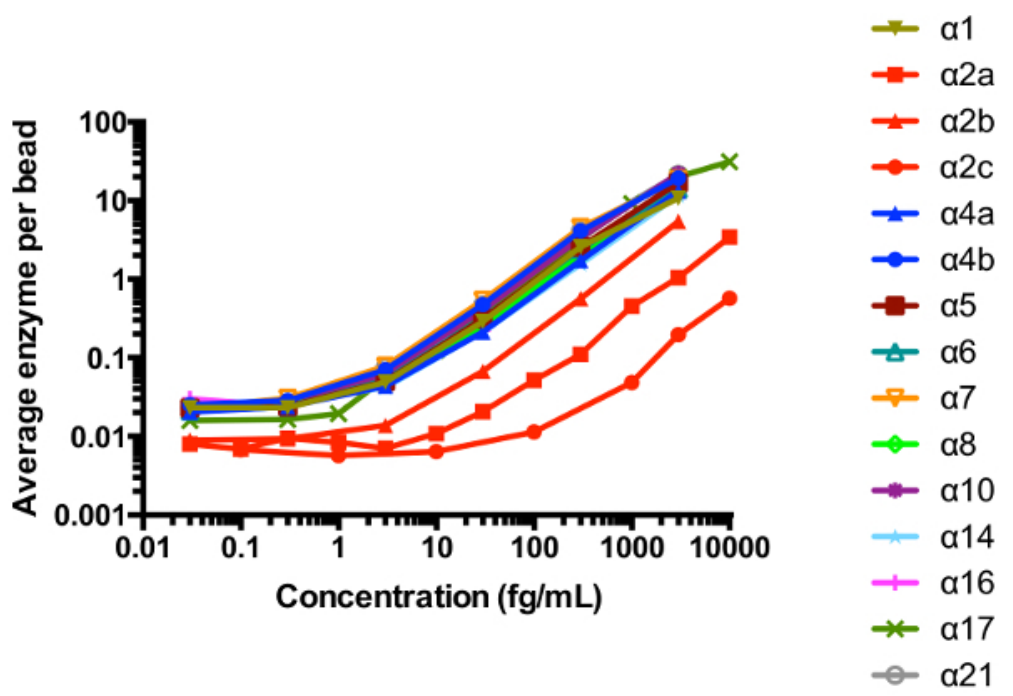

Figure 4: Specificity and sensitivity of the optimized IFN $\alpha$ single molecule array assay. (A) IFN- $\beta$, IFN- $\lambda 1$, IFN- $\lambda 2$, IFN- $\omega$, and IFN- $\gamma$ recombinant proteins were tested, together with (B) 16 subtypes of IFN- $\alpha$, including three IFN- $\alpha 2$ types (IFN- $\alpha 2 a$, IFN- $\alpha 2 b$, and IFN- $\alpha 2 c)$. Adapted from Rodero et al. 2017. Please click here to view a larger version of this figure.

2. Assess the reproducibility of the optimized assay by performing three independent replicate experiments and assessing inter-assay variability (Figure 5).

3. Calculate the LOD of the assay

NOTE: The LOD was calculated using the mean of the three blanks +3 standard deviations (SD), thus obtaining a value of $0.23 \mathrm{fg} / \mathrm{mL}$. As the standard sample dilution factor is $1: 3$, the inclusion of the dilution factor gives an LOD of $0.69 \mathrm{fg} / \mathrm{mL}$. 


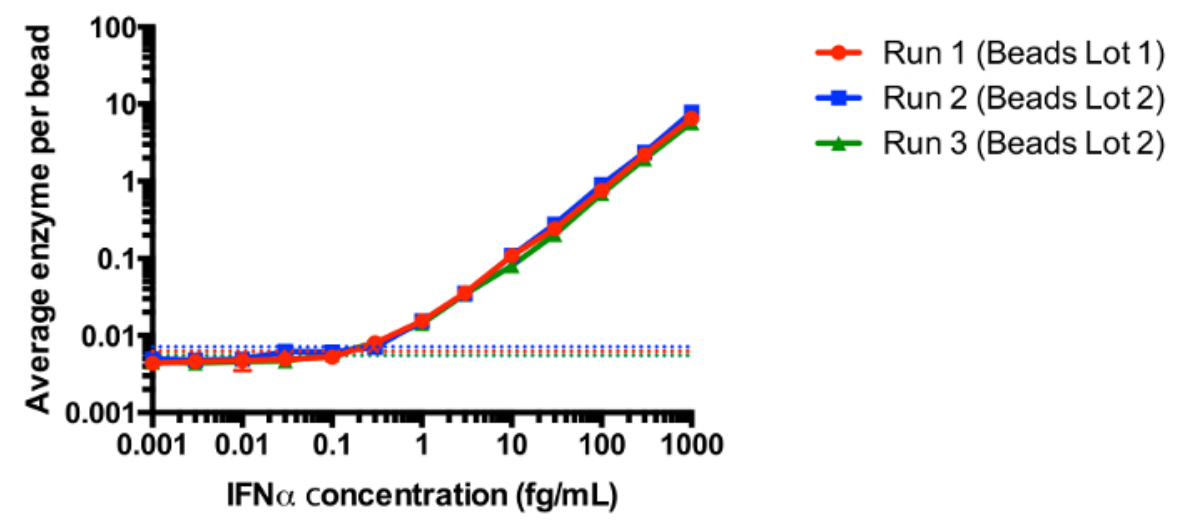

Figure 5: Reproducibility of the optimized pan-IFN- $\alpha$ single molecule array assay. Three independent runs were performed using two different lots of beads. For the second lot, two independent experiments were performed. Each measurement was acquired in duplicates. The dotted line represents the LOD, defined by mean blank average enzyme per bead + SD of all runs. IFN- 17 was used as a reference, taking into account that the derived standard curve is representative of all other IFN- $\alpha$ subtypes, as shown in Figure $4 \mathbf{b}$. Plot shows mean value and $\mathrm{SD}$ (error bars). Dotted lines show LOD for the different runs; Run 1: $0.073 \mathrm{fg} / \mathrm{mL} A E B=0.006238$, Run 2: $0.113 \mathrm{fg} / \mathrm{mL} A E B=0.007119, \mathrm{Run} 3$ : $0.043 \mathrm{fg} / \mathrm{mL} A E B=0.05518)$. Adapted from Rodero et al. 2017. Please click here to view a larger version of this figure.

\section{Protein Competition Assay}

1. Perform a protein competition assay (described in Figure 6 legend) to further demonstrate the specificity of the assay. NOTE: Plasma samples from patients with SLE $(n=5)$ were used.

1. When viruses are suspected to be present in the biological sample, prepare inactivation buffer by adding $200 \mu \mathrm{L}$ of a non-ioinic surfactant $(0.5 \%$ nonidet P40 substitute) to $40 \mathrm{~mL}$ Detector/Sample diluent, and vortex vigorously.

2. Centrifuge biological samples containing the analyte of interest at $10,000 \mathrm{~g}$ for $15 \mathrm{~min}$ at $4{ }^{\circ} \mathrm{C}$ to remove cellular debris.

3. Mix $185 \mu \mathrm{L}$ Detector/Sample diluent or inactivation buffer with $100 \mu \mathrm{L}$ biological sample (final dilution factor 3 ) and $15 \mu \mathrm{L}$ anti-IFN- $\alpha$ antibody $A$ (initial concentration $1 \mathrm{mg} / \mathrm{mL}$, final concentration $50 \mathrm{ug} / \mathrm{mL}$ ) or buffer. Incubate for $30 \mathrm{~min}$ at room temperature.

4. Run samples with and without anti-IFN- $\alpha$ antibody in the single molecule array analyser as described above.

NOTE: In case of signal saturation, samples should be further diluted. Also, $300 \mu \mathrm{L}$ is the volume required for duplicate analysis. 


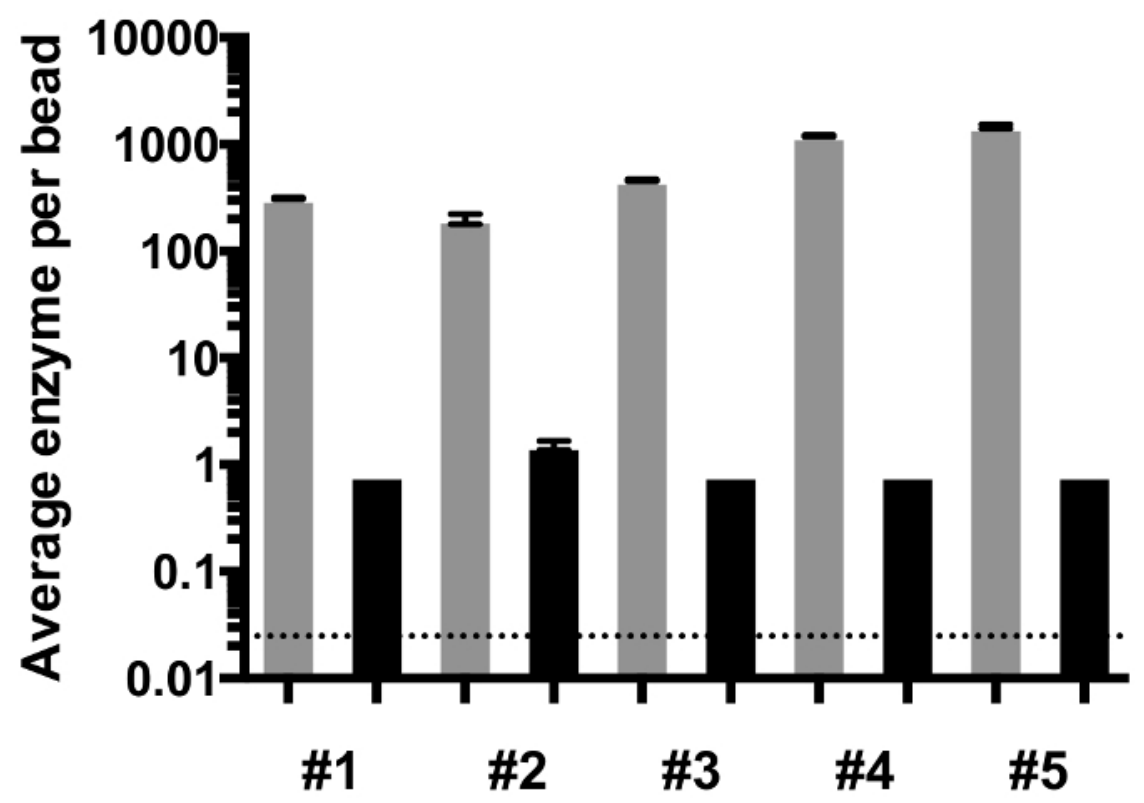

\section{Donor}

Figure 6: Protein competition assay. Competition experiments were performed using samples from five different SLE patients. Biological samples were centrifuged at $10.000 \mathrm{~g}$ for $15 \mathrm{~min}$ at $4{ }^{\circ} \mathrm{C}$. They were diluted $1 / 3$ with Detector/Sample diluent containing NP40 for viral inactivation. $15 \mu \mathrm{l}$ of anti-IFN- $\alpha$ antibody $A$ (initial concentration $1 \mathrm{mg} / \mathrm{mL}$, final concentration $50 \mu \mathrm{g} / \mathrm{mL}$ ) or buffer were added to a total volume of $300 \mu \mathrm{L}$. Incubation was performed at room temperature for $30 \mathrm{~min}$. Control group is shown in grey and samples treated with anti-IFN- $\alpha \mathrm{A}$ antibody are shown in black. Graph shows mean value and SD (error bars). Dotted line represents LOD $(A E B=0.024774,0.8037 \mathrm{fg} / \mathrm{mL})$. Adapted from Rodero et al. 2017 Please click here to view a larger version of this figure.

\section{Representative Results}

In summary, a pan-IFN- $\alpha$ single molecule array assay with a limit of detection of $0.69 \mathrm{fg} / \mathrm{mL}$, using a 2-step configuration with capture beads coated with $0.3 \mathrm{mg} / \mathrm{mL}$ of anti-IFN- $\alpha$ A antibody and anti-IFN- $\alpha$ B detection antibody biotinylated at a biotin:antibody ratio of 30 was developed. The concentrations used for biotinylated detection antibody and SBG were $0.3 \mu \mathrm{g} / \mathrm{mL}$ and $150 \mathrm{pM}$, respectively. This highly specific assay is capable of detecting all 13 IFN- $\alpha$ subtypes and does not cross react with other type of IFNs. Thus, while it is not possible to identify and quantify each individual species of IFN- $\alpha$, all of them can be detected and measured together giving a total concentration value for IFN- $\alpha$, that comprises the 13 different subclasses.

To explore the potential diagnostic value of this newly developed assay, IFN- $\alpha$ protein in plasma and serum from healthy individuals were measured and compared with samples from patients suffering from SLE and JDM. As illustrated in Figure 7, high levels of IFN- $\alpha$ protein were detected in both disease cohorts as compared to healthy controls. The dotted line indicates the LOD of a conventional commercially available ELISA, illustrating how this approach would not detect IFN- $\alpha$ protein in these patient groups despite the known associations of this cytokine with these phenotypes. Furthermore, IFN- $\alpha$ could be quantified over 5 logs of magnitude, illustrating the wide dynamic range of the assay, with detectable levels between $1-10 \mathrm{fg} / \mathrm{mL}$ confirming the highly sensitive nature of the assay. 


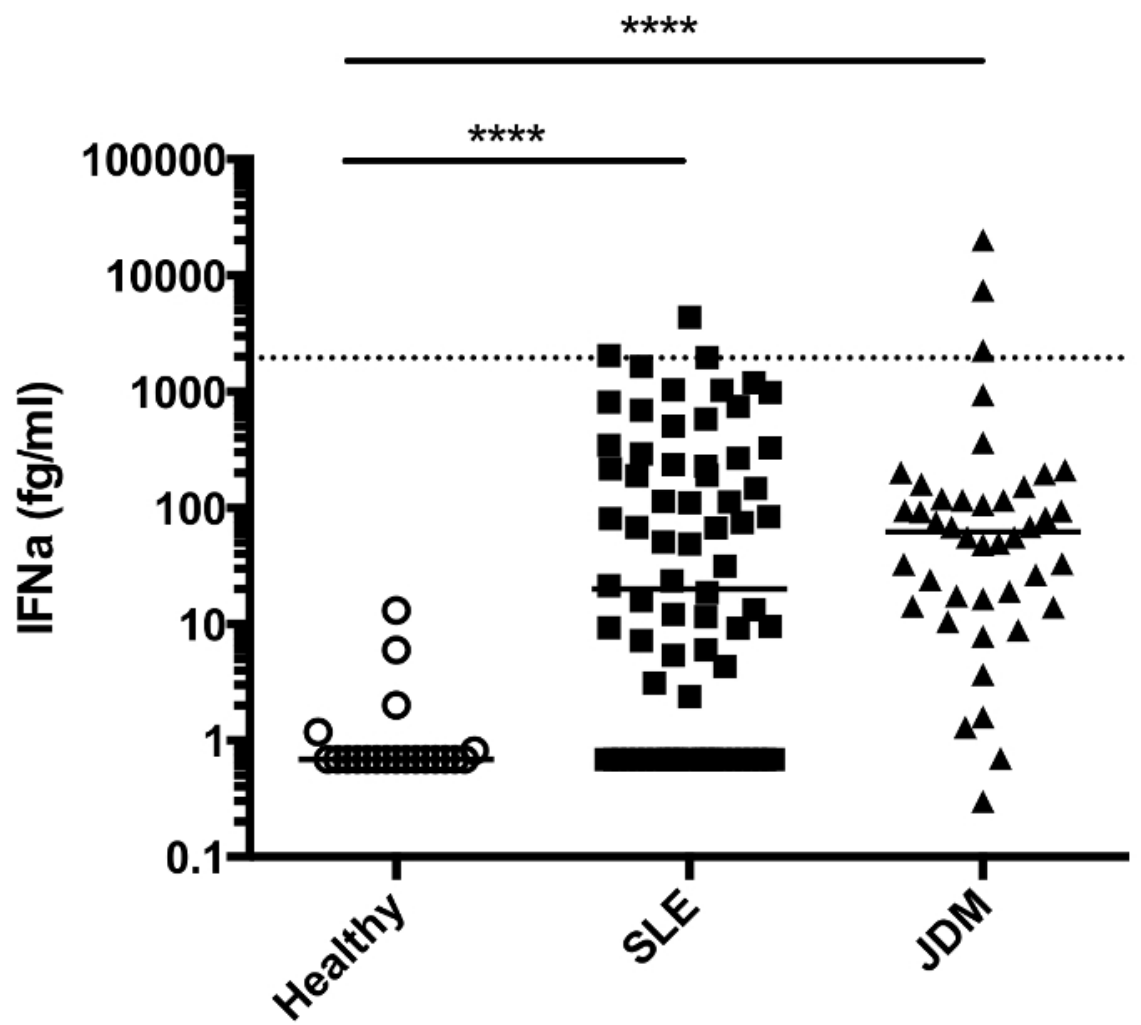

Figure 7: Quantification of IFN- $\alpha$ protein in plasma and serum from patient cohorts. This figure has been modified from Rodero et al. 2017. Plasma from healthy controls $(n=20)$ and patients suffering from SLE $(n=72)$ and JDM $(n=43)$ were tested with the pan-IFNa single molecule array assay. Analysis was performed using one-way ANOVA test (Kruskal-Wallis) and Dunn's multiple comparison testing between groups. Median is depicted. Dotted line indicates LOD of a reference human anti-IFN- $\alpha$ ELISA $(1.95 \mathrm{pg} / \mathrm{mL}=1950 \mathrm{fg} / \mathrm{mL})$. Please click here to view a larger version of this figure.

\begin{tabular}{|c|c|c|}
\hline Step & Considerations & Reference \\
\hline \multirow[t]{3}{*}{ 1. Antibody pair choice } & Target different epitopes & \multirow[t]{3}{*}{ Table 2} \\
\hline & High affinity & \\
\hline & Fast $\mathrm{K}_{\text {on }} /$ Slow $\mathrm{K}_{\text {off }}$ & \\
\hline 2. Antibody pair orientation & \multirow{3}{*}{$\begin{array}{l}\text { Choose conditions with the lowest Limit of } \\
\text { Detection }\end{array}$} & \multirow[t]{3}{*}{ Figure 1} \\
\hline 3. Capture antibody concentration & & \\
\hline 4. Biotin:Detector antibody ratio & & \\
\hline 5. 2 vs. 3-step configuration & $\begin{array}{l}\text { Choose condition with the highest } \\
\text { Signal:Background ratio }\end{array}$ & Figure 2 \\
\hline 6. Detector antibody concentration & \multirow{2}{*}{$\begin{array}{l}\text { Choose conditions with the lowest Limit of } \\
\text { Detection }\end{array}$} & \multirow[t]{2}{*}{ Figure 3} \\
\hline 7. SBG concentration & & \\
\hline 8. Specificity & Assess cross-reactivity & \multirow[t]{2}{*}{ Figure 4} \\
\hline 9. Sensitivity & Assess recognition of subtypes (if applicable) & \\
\hline 10. Reproducibility & Assess assay variability & Figure 5 \\
\hline
\end{tabular}

Table 1: Summary of steps for development and optimization of a single molecule array assay. This table summarizes the different steps required for the development and optimization of a single molecule array assay, from the initial choice of antibody pair until the assessment of reproducibility. 


\begin{tabular}{|l|l|l|l|l|}
\hline Antigen & $\mathbf{8 H 1}(\mathbf{A})$ & $\mathbf{1 2 H 5}(\mathbf{B})$ & Sifalimumab & Rontalizumab \\
\hline IFNa1 & 28.3 & 51.3 & 460 & 22.63 \\
\hline IFNa2 & 2563 & 10.7 & 9.02 & 2.15 \\
\hline IFNa4 & 5.11 & 2.99 & 35.35 & 325.3 \\
\hline IFNa5 & 2.01 & 19.6 & 93.29 & 2.49 \\
\hline IFNa6 & 64.7 & 3.03 & 4.97 & - \\
\hline IFNa7 & 0.9 & 0.63 & 233.1 & - \\
\hline IFNa8 & 302 & 0.83 & 691 & 10.86 \\
\hline IFNa10 & 2.54 & 0.71 & 43.2 & - \\
\hline IFNa14 & 3224 & 2.1 & 14.52 & 0.9 \\
\hline IFNa16 & 1.83 & 32.99 & 59.18 & 28.65 \\
\hline IFNa17 & 2.21 & 0.77 & 890.9 & 23.86 \\
\hline IFNa21 & 2.78 & 12.87 & 1769 & 5.8 \\
\hline
\end{tabular}

Table 2: Pan-alpha antibody selection. IC50 ( $\mathrm{ng} / \mathrm{mL}$ ) determined using the interferon-stimulated response element (ISRE)-Luciferase neutralization assay. Table shows IC50 values of mAbs used in single molecule array assay for all IFN- $\alpha$ subtypes. 10,000 HEK 293 MSR cells were seeded in white half-area 96-well plates and reverse-transfected with 50 ng premixed ISRE-Firefly luciferase reporter and Renilla luciferase constructs using transfection reagents according to the manufacturer's instructions. The luciferase-expressing construct served as an internal normalization control. Cells were incubated overnight in Reduced Serum Medium supplemented with $0.1 \mathrm{mM}$ nonessential amino acids, $1 \mathrm{mM}$ sodium pyruvate, $0.5 \%$ fetal bovine serum at $37^{\circ} \mathrm{C}, 5 \% \mathrm{CO}_{2}$ in a humidified atmosphere. After overnight incubation, cells were stimulated for $24 \mathrm{~h}$ with medium containing mixtures of recombinant human IFN- $\alpha$ with or without anti-IFN- $\alpha$ mAbs or control IgG that had been preincubated for $1 \mathrm{~h}$ at $37^{\circ} \mathrm{C}$. After $24 \mathrm{~h}$ of stimulation, dual luciferase reporter assays were performed according to the manufacturer's instructions. " - » Not determined. Sifalimumab is a fully human, immunoglobulin $\mathrm{G} 1 \mathrm{k}$ monoclonal antibody that binds to and neutralizes the majority of IFN- $\alpha$ subtypes; Rontalizumab is a humanized monoclonal antibody against IFN- $\alpha$. Adapted from Meyer et al. 2016 and Rodero et al. 2017.

Supplementary Table 1: Selection of antibody orientation, capture antibody concentration on beads and biotinylation ratio. The two possible different configurations were tested, using the anti-IFN- $\alpha$ A as capture antibody and anti-IFN- $\alpha$ B as detection antibody (A), and vice versa (B). IFNa-2c was used as antigen. Different capture antibody concentrations as well as biotin:antibody (B:A) ratios were also tested for both configurations. Saturation (Sat). Orange: AEB values that were used for LOD calculation; these concentrations were considered blank as the AEB values remained steady. LOD was calculated as Mean Blank + 3SD. Please click here to download this file.

Supplementary Table 2: Test of 2 vs 3-step configuration. The 2 and 3 -step configurations were assessed using IFNa-2c as antigen. AEB values as well as signal/background rations $(S / B)$ are shown for both conditions. Please click here to download this file.

Supplementary Table 3: Detector and SBG concentration optimization. Three different concentrations of biotinylated detector antibody (0.1, 0.3 , and $0.6 \mu \mathrm{g} / \mathrm{mL})$ together with three different concentrations of SBG $(50,150$, and $250 \mathrm{pM})$ were assessed. AEB values are shown for the nine tested conditions. Orange: AEB values that were used for LOD calculation; these concentrations were considered blank as the AEB values remained steady. LOD was calculated as Mean Blank + 3SD. Please click here to download this file.

Supplementary Table 4: Specificity and sensitivity of the optimized IFNa single molecule array assay. Average enzyme per beads values are shown when IFN- $\beta$, IFN- $\lambda 1$, IFN- $\lambda 2$, IFN- $\omega$, and IFN- $\gamma$ recombinant proteins were tested (A), together with the 16 subtypes of IFN- $\alpha$ (B). « - » Not determined. Please click here to download this file.

Supplementary Table 5: Reproducibility of the optimized IFNa single molecule array assay. The mean AEB values for all three independent runs are shown up to a concentration of $10.000 \mathrm{fg} / \mathrm{mL}$. « - » Not determined. Saturation (Sat). Please click here to download this file.

Supplementary Table 6: Protein competition assay. Average enzyme per beads values are shown for all conditions tested. Measurements were done in duplicate. Please click here to download this file.

\section{Discussion}

Herein, we described the development and validation of a highly reproducible, ultrasensitive single molecule array digital ELISA for direct quantification of IFN- $\alpha$ protein in human samples (steps summarized in Table 1). One of the most critical steps in the development of the assay is the choice of antibody pair ${ }^{16}$, with the characteristics in terms of kinetics and epitope binding being key to a successful assay. It is important to avoid the use of paired monoclonal antibodies that target the same epitope or that cause steric impediment. Polyclonal antibodies could be used as detection antibodies to overcome such limitations. If at any given step the desired sensitivity is not achieved, further optimization possibilities should be considered. This may include the use of alternative antibody pairs, changes in parameters such as protein type (e.g. $\mathrm{BSA}<$ casein), $\mathrm{pH}(6.0$ - 8.5), ionic strength, buffering capacity (e.g. $\mathrm{NaCl}$ and phosphate concentrations), carrier beads, and/or presence of surfactants. A wide range of parameters con be optimized when developing a single molecule array assay. However, overall, conditions that give high signal:background ratios and minimal LODs are the ones preferred (see Figure 1, Figure 2, and Figure 3).

Regarding specificity, the IFN- $\alpha$ assay showed no cross reactivity for any other IFNs tested $(\beta, \gamma, \lambda 1, \lambda 2, \omega)$ (Figure 4a) and was capable of detecting all 13 IFN- $\alpha$ subtypes (Figure 4b). However, the assay showed a lower affinity for the IFN- $\alpha 2$ subtype, (Figure $4 b$ and Supplementary 
Table 4). Interestingly, different sensitivities for the different classes of IFN- $\alpha 2(a, b, c)$ were also observed, which may be due to distinct manufacturing procedures or different amino acid sequences, as the IFN- $\alpha 2$ subtypes were obtained from different commercial suppliers. With this sole exception, all the IFN- $\alpha$ species gave very similar responses. The specificity of the assay was further demonstrated by pre-treatment of the samples with the anti-IFN- $\alpha$ A clone, which abrogated the signal (Figure 6 and Supplementary Table 6).

One of the main advantages of this technology is that any analyte of interest can potentially be targeted ${ }^{16}$. Furthermore, different biological specimens can be tested, such as serum, plasma, cerebrospinal fluid, cellular lysates, culture supernatants ${ }^{31}$ and even breath $^{32}$. Usually, a 1:3 dilution of plasma is performed to avoid potential clogging of the single molecule array analyzer. However, the analyte of interest could be present at very low concentrations in the relevant biological sample and higher concentrations of sample might be required (depending on assay sensitivity $)^{33}$. Although there is potential for multiplexing while maintaining good sensitivity ${ }^{34}$, it is a more challenging process and assays for measuring greater than 6 proteins within the same experiments have yet to be developed ${ }^{35}$.

The ability to detect and quantify cytokines and other biological relevant proteins at such low concentrations opens up a whole new range of applications $^{33,36}$. It is well known that numerous proteins exert their effects even at very low concentrations, which up until now were below the limit of detection of the best ELISAs ${ }^{37}$. While other immunoassay technologies offer advantages over conventional ELISA ${ }^{19}$, we demonstrate here that single molecule array digital ELISA is a reproducible and robust platform for the ultrasensitive detection of low concentration cytokines in human samples. As such, this technology offers enormous potential for biomarker discovery and improved patient management of a wide range of diseases.

\section{Disclosures}

The authors have nothing to disclose.

\section{Acknowledgements}

DD and YJC acknowledge support from the ANR (Project IFNX, no. CE17001002) and ImmunoQure AG for providing monoclonal antibodies. We thank Brigitte Bader-Meunier, Nathalia Bellon, Christine Bodemer, Alex Belot, Isabelle Melki, and Pierre Quartier for providing clinical samples. YJC acknowledges the European Research Council (GA 309449: Fellowship to YJC), and a state subsidy managed by the National Research Agency (France) under the "Investments for the Future" program bearing the reference ANR-10-IAHU-01.

\section{References}

1. Isaacs, A., \& Lindenmann, J. Classics in Oncology Virus Interference : I. The Interferon. Proc. R. Soc. London. Ser. B, Biol. Sci. 147, 258-67 (1957).

2. Isaacs, A., Lindenmann, J., Valentine, R. C., \& Alerts, E. Pillars Article: Virus Interference. II. Some Properties of Interferon. Proc. R. Soc. London. Ser. B, Biol. Sci. 147, 268-73 (1957).

3. Hunt, D. et al. Thrombotic Microangiopathy Associated with Interferon Beta. N. Engl. J. Med. 370, 1270-71 (2014).

4. Hooks, J. J. et al. Immune Interferon in the Circulation of Patients with Autoimmune Disease. N. Engl. J. Med. 301, 5-8 (1979).

5. Greenberg, S. A. et al. Interferon-alpha/beta Mediated Innate Immune Mechanisms in Dermatomyositis. Ann. Neurol. 57, 664-78 (2005).

6. Crow, Y. J. Type I interferonopathies : a novel set of inborn errors of immunity. Ann. N. Y. Acad. Sci. 1238, 91-8 (2011).

7. Rodero, M. P., \& Crow, Y. J. Type I interferon - mediated monogenic autoinflammation: The type I interferonopathies, a conceptual overview. J. Exp. Med. 213, 2527-38 (2016).

8. Lewis, J. A. A sensitive biological assay for interferons. J. Immunol. Methods. 185, 9-17 (1995).

9. Meager, A. Biological assays for interferons. J. Immunol. Methods. 261, 21-36 (2002).

10. Hua, J., Kirou, K., Lee, C., \& Crow, M. K. Functional Assay of Type I Interferon in Systemic Lupus Erythematosus Plasma and Association With Anti - RNA Binding Protein Autoantibodies. Arthritis Rheumatol. 54, 1906-16 (2006).

11. Niewold, T. B., Kariuki, S. N., Morgan, G. A., Shrestha, S., \& Pachman, L. M. Elevated serum interferon-alpha activity in juvenile dermatomyositis: associations with disease activity at diagnosis and after thirty-six months of therapy. Arthritis Rheumatol. 60, 1815-24 (2009).

12. Seo, Y., Kim, G., Kwak, H., \& Nam, J. Validation of a HeLa Mx2 / Luc Reporter Cell Line for the Quantification of Human Type I Interferons. Pharmacology. 84, 135-144 (2009).

13. Li, Y. et al. Monocyte surface expression of Fcy receptor RI ( CD64 ), a biomarker reflecting type-l interferon levels in systemic lupus erythematosus. Arthritis Res. Ther. 12, 1-12 (2010).

14. Berger-Rentsch, M., \& Zimmer, G. A Vesicular Stomatitis Virus Replicon-Based Bioassay for the Rapid and Sensitive Determination of MultiSpecies Type I Interferon. PLoS One. 6, e25858 (2011).

15. Rissin, D. M. et al. Single-molecule enzyme-linked immunosorbent assay detects serum proteins at subfemtomolar concentrations. Nat. Biotechnol. 28, 595-599 (2010)

16. Wu, D., Milutinovic, M. D., \& Walt, D. R. Single molecule array (Simoa) assay with optimal antibody pairs for cytokine detection in human serum samples. R. Soc. Chem. 140, 6277-82 (2015).

17. Scientific Principle of SimoaTM (Single Molecule Array) Technology. Whitepaper 1.0. 1-2 (2013).

18. Chang, L. et al. Single molecule enzyme-linked immunosorbent assays: Theoretical considerations. J. Immunol. Methods. 378, 102-115 (2012).

19. Yeung, D. et al. Evaluation of highly sensitive immunoassay technologies for quantitative measurements of sub-pg / $\mathrm{mL}$ levels of cytokines in human serum. J. Immunol. Methods. 437, 53-63 (2016).

20. Song, L. et al. Single molecule measurements of tumor necrosis factor $\alpha$ and interleukin- 6 in the plasma of patients with Crohn's disease. J. Immunol. Methods. 372, 177-186 (2011). 
21. Meissner, E. G., Decalf, J., Casrouge, A., \& Masur, H. Dynamic Changes of Post-Translationally Modified Forms of CXCL10 and Soluble DPP4 in HCV Subjects Receiving Interferon-Free Therapy. PLoS One. 10, e0133236 (2015).

22. Decalf, J. et al. Inhibition of DPP 4 activity in humans establishes its in vivo role in CXCL 10 post-translational modification: prospective placebo-controlled clinical studies. EMBO Mol. Med. 8, 679-683 (2016).

23. Rabing Brix Petersen, E. et al. Rhodopsin in plasma from patients with diabetic retinopathy - development and validation of digital ELISA by Single Molecule Array ( Simoa ) technology. J. Immunol. Methods. 446, 60-69 (2017).

24. Disanto, G. et al. Serum Neurofilament Light: A Biomarker of Neuronal Damage in Multiple Sclerosis. Ann. Neurol. 81, 857-70 (2017).

25. Song, L. et al. A digital enzyme-linked immunosorbent assay for ultrasensitive measurement of amyloid- $\beta 1$ - 42 peptide in human plasma with utility for studies of Alzheimer 's disease therapeutics. Alzheimers. Res. Ther. 8, 1-15 (2016).

26. Passaes, C. et al. Ultrasensitive HIV-1 p24 Assay Detects Single Infected Cells and Differences in Reservoir Induction by Latency Reversal Agents. J. Virol. 91, e02296-16 (2017).

27. Song, L. et al. Direct Detection of Bacterial Genomic DNA at Sub-Femtomolar Concentrations Using Single Molecule Arrays. Anal. Chem. 85, 1932-9 (2013).

28. Cohen, L., Hartman, M. R., Amardey-wellington, A., \& Walt, D. R. Digital direct detection of microRNAs using single molecule arrays. Nucleic Acids Res. 45, e137 (2017).

29. Meyer, S. et al. AIRE-Deficient Patients Harbor Unique High-Affinity Disease-Ameliorating Autoantibodies. Cell. 166, $582-595$ (2016)

30. Homebrew Assay Development Guide Simoa HD-1 Analyzer \& Quanterix SR-X. User-0021 08. Quanterix corporation. (2017).

31. Rodero, M. P. et al. Detection of interferon alpha protein reveals differential levels and cellular sources in disease. J. Exp. Med. 214, 1547-1555 (2017).

32. Pleil, J., Angrish, M., \& Madden, M. Immunochemistry for high-throughput screening of human exhaled breath condensate ( EBC ) media: implementation of automated Quanterix SIMOA instrumentation. J. Breath Res. 9, 047108 (2015).

33. Schiess, R., Wollscheid, B., \& Aebersold, R. Targeted Proteomic Strategy for Clinical Biomarker Discovery. Mol. Oncol. 3, 33-44 (2009).

34. Wilson, D. H. et al. The Simoa HD-1 Analyzer: A Novel Fully Automated Digital Immunoassay Analyzer with Single-Molecule Sensitivity and Multiplexing. J. Lab. Autom. 21, 533-547 (2016).

35. Rivnak, A. J. et al. A fully-automated, six-plex single molecule immunoassay for measuring cytokines in blood. J. Immunol. Methods. 424, 20-27 (2015).

36. Anderson, N. L., \& Anderson, N. G. The Human Plasma Proteome. History, character, and diagnostic prospects. Mol. Cell. proteomics. 1, 845-867 (2002).

37. Tighe, P. J., Ryder, R. R., Todd, I., \& Fairclough, L. C. ELISA in the multiplex era: Potentials and pitfalls. Proteomics Clin. Appl. 9, 406-422 (2015). 